OPEN ACCESS

Edited by:

Qiongjie Zhou,

Fudan University, China

Reviewed by:

Udo Jeschke,

Ludwig-Maximilians-Universität

München, Germany

Gendie Lash,

Guangzhou Medical University, China

*Correspondence:

Liping Feng

liping.feng@duke.edu

Jun J. Zhang

junjimzhang@sina.com

${ }^{\dagger}$ These authors have contributed equally to this work

Specialty section: This article was submitted to

Reproduction,

a section of the journal

Frontiers in Endocrinology

Received: 13 April 2021

Accepted: 12 July 2021

Published: 28 July 2021

Citation:

Marchese MJ, Li S, Liu B, Zhang JJ and Feng $L$ (2021) Perfluoroalkyl

Substance Exposure and the BDNF Pathway in the Placental Trophoblast.

Front. Endocrinol. 12:694885.

doi: 10.3389/fendo.2021.694885

\section{Perfluoroalkyl Substance Exposure and the BDNF Pathway in the Placental Trophoblast}

\author{
Melissa J. Marchese ${ }^{1 \dagger}$, Shuman $\mathrm{Li}^{2 \dagger}$, Bin Liü ${ }^{2}$, Jun J. Zhang ${ }^{2 *}$ and Liping Feng ${ }^{1,2 *}$ \\ ${ }^{1}$ Department of Obstetrics and Gynecology, Duke University, Durham, NC, United States, ${ }^{2}$ Ministry of Education-Shanghai \\ Key Laboratory of Children's Environmental Health, School of Public Health, Shanghai Jiao-Tong University School of \\ Medicine, Shanghai, China
}

Background: Per- and polyfluoroalkyl substances (PFAS) are persistent organic pollutants that have become globally ubiquitous in humans and the environment. In utero PFAS exposure is associated with neurodevelopmental effects; however, the mechanism is poorly understood. Brain-derived neurotrophic factor (BDNF) signaling is critical to fetal neurodevelopment during pregnancy and maintains important regulatory roles later in life. This study aims to characterize placental BDNF signaling and investigate whether PFAS exposure disrupts the signaling pathway in placental trophoblast cells.

Methods: The expression and localization of BDNF receptors-p75 ${ }^{\text {NTR }}$ and TrkB-in first trimester and term human placentas and trophoblast cells were investigated by immunofluorescence staining. To assess the effects of PFAS exposure on the BDNF pathway, BeWo cells were treated with PFAS mixtures that mimicked blood levels in a highly exposed population and major PFAS compounds in the mixture at 0.01, 0.1, 1, and $10 \mu \mathrm{M}$ concentrations. Changes in pro-BDNF levels and phosphorylation of TrkB receptors were examined by Western blot.

Results: In first trimester human placentas, TrkB and $\mathrm{p} 75^{\mathrm{NTR}}$ receptors were primarily localized to syncytiotrophoblast and cytotrophoblast cells. At term, TrkB and p75 NTR receptors were primarily observed in the placental villous stroma. TrkB receptor staining in trophoblasts was reduced at term, while $\mathrm{p} 75^{\mathrm{NTR}}$ receptor staining was negative. TrkB receptors were confined to the nuclear and perinuclear spaces, and phosphorylation occurred at the Tyr816 residue in BeWo cells. Exposure to PFOS, PFOA, PFBS, and the six-PFAS mixture did not significantly affect BDNF levels or activation (phosphorylation) of TrkB. Treating cells with $1 \mu \mathrm{M}$ and $10 \mu \mathrm{M}$ of PFNA resulted in increased TrkB phosphorylation compared to unexposed controls, but BDNF levels were unchanged.

Conclusions: BDNF receptors are present in different regions of human placental villi, indicating diverse functions of BDNF signaling in placental development. Our findings suggest that the BDNF pathway in placental trophoblast cells is not disrupted by exposures to PFOS, PFOA, PFBS, and a PFAS mixture, but may be affected by PFNA 


\section{exposures. Further investigation is needed on how PFAS affects other critical signaling} pathways during fetal neurodevelopment.

Keywords: Perfluoroalkyl substances, BDNF, TrkB, placenta, trophoblast

\section{INTRODUCTION}

Per- and polyfluoroalkyl substances (PFAS) are synthetic carbon fluorine compounds used in industry and commerce since the 1940s (1). The stability and surfactant properties exhibited by PFAS have led to widespread use in products from stain-resistant textiles to firefighting foam-making them ubiquitous in the environment $(2,3)$. Biomonitoring data have demonstrated global accumulation in humans and biota via contaminated drinking water, food and its packaging, outdoor air, house dust, and soil (4-6). Previous studies estimate over 95\% of Americans to have detectable levels of PFAS in their blood, but certain communities face disproportionate exposure risk (7-9). One such affected population is in Pittsboro, North Carolina, where sum PFAS concentrations up to $1,076 \mathrm{ng} / \mathrm{L}$ and $270.8 \mathrm{ng} / \mathrm{L}$ were measured at drinking water intakes and in finished household drinking water, respectively. ${ }^{1}$ These numbers are over 30 times higher than those in the neighboring city of Durham and are strikingly higher than surrounding cities. ${ }^{1}$ The blood levels of PFAS are between two and four times higher in Pittsboro residents than the general United States population. ${ }^{2}$

Concern surrounding PFAS has risen among affected North Carolina residents due to the potential deleterious human health effects associated with exposure. A growing body of robust laboratory and epidemiologic data link PFAS to increased risk of cancer, immune system dysfunction, poor antibody response to vaccines, hormone disruption, kidney disease, thyroid disorders, high cholesterol, pregnancy-induced hypertension, preeclampsia, asthma, and decreased fertility (10). Fetuses are particularly vulnerable to PFAS exposure because PFAS readily cross the placental barrier and are transferred to developing babies (11-13). Early-life exposure to various PFAS compounds is associated with an array of developmental and neurobehavioral impacts. Previous early childhood studies observed associations between PFAS exposure and delays in gross motor development (14), worsened visual motor abilities (15), lower IQ test scores (16), externalizing behavioral difficulties (17-19), poorer executive functioning (20), neuropsychological developmental problems (21), and attention deficit hyperactivity disorder (ADHD) and related diagnostic symptoms $(19,22,23)$. Other observational studies of child neurobehavior report mixed or null associations (24-29). Despite the effects of PFAS on human development gaining more attention, a consensus on the neurodevelopmental consequences

\footnotetext{
${ }^{1}$ https://www.northcarolinahealthnews.org/2019/07/30/pfas-shows-up-in-hawriver-pittsboro-water-but-little-local-outcry/

${ }^{2}$ https://www.northcarolinahealthnews.org/2020/10/29/duke-study-finds-highpfas-levels-in-pittsboro-residents-blood/
}

of exposure has yet to be reached and further investigation is necessary.

Although the mechanism of neurotoxicity remains unclear, one pathway that may be implicated is the production of brainderived neurotrophic factor (BDNF). BDNF is essential to mammalian nervous system development and function (30). BDNF primarily interacts with two receptors, $\mathrm{p} 75^{\mathrm{NTR}}$ and tropomyosin sensitive receptor kinase B $(\operatorname{TrkB})(31,32)$. Abnormalities in the BDNF pathway have been linked to psychiatric disorders such as ADHD, schizophrenia, major depression, autism, bipolar disorder, Alzheimer's, and Parkinson's diseases (1, 5, 33-38). Reduced expression of BDNF has been shown to impair working memory, reduce volume of the cerebellum and hippocampus, and diminish cognitive ability (39). Neurotrophins like BDNF play a role in both prenatal and postnatal brain development and may offer neuroprotective effects (40-42). BDNF supports differentiation of neuronal cell types and influences synaptic properties in the peripheral and central nervous systems during early development $(41,43,44)$. During pregnancy, the majority of $\mathrm{BDNF}$ is derived from either the mother or the placenta and regulates fetal and placental development (45-48). BDNF contributes to fetal growth by promoting survival, proliferation, migration, and differentiation of cytotrophoblasts in addition to angiogenesis, vessel stabilization, regulation of growth factors, and control of energy homeostasis (48-51). Changes in the BDNF pathway may lead to abnormal placental development and pregnancy complications such as preeclampsia $(52,53)$. However, the characteristics of the BDNF expression in the human placenta are poorly understood. $B D N F$ is a plastic gene whose expression is highly responsive to external stimuli and environmental exposures $(30,35,37,54)$. Significant PFASattributable alterations in BDNF expression have been observed in several animal model and cell studies, but conclusions are largely inconsistent (55-59).

This study aims to characterize the BDNF pathway in human placental tissues and trophoblast cell lines. Further, we seek to investigate how the BDNF pathway in placental trophoblast cells is affected by exposures to a PFAS mixture-which models the exposure of Pittsboro, North Carolina residents (based on blood levels)—and major PFAS compounds in this mixture.

\section{MATERIALS AND METHODS}

\section{Chemicals and Reagents}

Potassium nonafluoro-1-butanesulfonate (K+PFBS, CAS No. 29420-49-3), tridecafluorohexane-1-sulfonic acid potassium salt $(\mathrm{K}+\mathrm{PFHxS})$, and heptadecafluorooatanesulfonic acid potassium salt $(\mathrm{K}+\mathrm{PFOS})$ were purchased from Sigma-Aldrich (St. Louis, 
MO). Oerfluorohexanoic acid (PFHxA), perfluoro-n-octanoic acid (PFOA), perfluorononanoic acid (PFNA), and perfluorodecanoic acid (PFDA) were purchased from Synquest Laboratories (Alachua, FL). Product purity is above 95\%. Stock solutions of PFAS at 10,1,0.1, $0.01 \mathrm{mM}$ were prepared by dissolving PFAS compounds in ultrapure distilled water. A PFAS mixture was made based on the PFAS levels in blood samples collected from people living in Pittsboro, NC, in 2019 (Table 1). ${ }^{3}$ Forskolin (Wako Chemicals, Japan) stock solution was reconstituted in DMSO at $80 \mathrm{mM}$.

\section{Cell Culture and PFAS Treatments}

An immortalized human choriocarcinoma cell line (BeWo cells, gifted by Dr. Sallie Permar, Duke University, Durham, North Carolina) was cultured in Dulbecco's Modified Eagle MediumHams/F12 (DMEM/F12) media supplemented with 10\% Fetal Bovine Serum (FBS) and $1 \mathrm{x}$ antibiotic-antimycotic solution (Thermo Fisher Scientific). Cell culture and treatment conditions are described in our previous publications $(60,61)$. In short, after $60-70 \%$ confluency was reached, cells were treated for 48 hours with DMSO (1:2000 dilution) or $40 \mu \mathrm{M}$ forskolin (FSK) to induce cell fusion, thereby modeling syncytialization of cytotrophoblasts (CTB) during placental development. Culture media supplemented with fresh $40 \mu \mathrm{M}$ FSK was changed every 24 hours to ensure complete cell fusion. BeWo cells with and without FSK treatments were then treated with individual PFAS compounds at $0,0.01,0.1,1$, and $10 \mu \mathrm{M}$ concentrations or the PFAS mixture (1:1, 1:10, 1:50, 1:100 dilutions; Table 1) for 24 hours. These doses were chosen for cellular function studies based on human exposure levels. ${ }^{3}$ To ensure the effects on cellular functions are not due to cytotoxicity, we used doses at least 10 times lower than LD10 (61). The following methods for immunofluorescence staining and Western blot were performed as described in Marinello et al. (62).

\section{Immunofluorescence Staining of Placental Tissues}

First trimester placental tissues were collected from elective pregnancy termination patients without notifiable complications at 8-10 gestational weeks. The study protocol was approved by the Ethics Committees of Xinhua Hospital affiliated with Shanghai Jiao Tong University School of Medicine (IRB\# XHEC-C-2018-089) with the consent waiver to obtain deidentified tissue that was not to be used for clinical purposes. Term placental tissues were collected under the Duke University Institutional Review Board approval (IRB\# PRO00014627) with the consent waiver to obtain de-identified tissue that was not to be used for clinical purposes. The placentas were collected from women who underwent planned cesarean delivery at term (39 to 40 gestational weeks), without labor and current or previous pregnancy complications.

Sections of placental tissues were fixed and paraffin embedded. Tissue slides were deparaffinized with xylene followed by graded rehydration in ethanol and distilled water.

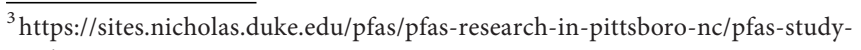
results/
TABLE 1 | PFAS mixture (ng/g) administered to cell cultures based on levels in blood samples collected from residents of Pittsboro, North Carolina.

\begin{tabular}{lc}
\hline PFOS & 12.10 \\
PFOA & 7.00 \\
PFHXS & 3.10 \\
PFNA & 1.80 \\
PFDA & 0.75 \\
PFHXA & 0.60 \\
Total & 25.35
\end{tabular}

Subsequently, the sections were subjected to heat-induced epitope retrieval by heating in antigen unmarking solution (Vector Laboratories, Inc, Burlingame, California) preheated to boiling for 20 minutes, followed by a 20 -minute cool-down period at room temperature. Slides were permeabilized and blocked with $1 \%$ BSA, $10 \%$ normal goat serum and $0.01 \%$ tween-20 in PBS for $60 \mathrm{~min}$ at room temperature. After blocking, the slides were incubated with primary antibodies in blocking buffer overnight at $4^{\circ} \mathrm{C}$ in humidified chambers. Primary rabbit anti-human syndecan 1 (SDC-1) antibody (Sigma, catalog no. HPA006185), mouse anti-human TrkB antibody (R \& D System, cat\#: MAB397), or p75NTR antibody (R \& D System, cat\#: MAB3671) was used at a 1:200 dilution. Goat anti-rabbit Alexa Fluo 488 secondary antibody and Goat anti-mouse Alexa Fluo 594 secondary antibody (Life Technologies, Carlsbad, CA) were used at 1:300 dilution. Nuclei were stained using NucBlue Fixed Cell ReadyProbes Reagent (DAPI, Invitrogen). Slides were mounted using ProLong Diamond Antifade Mountant (Invitrogen) and examined with a Leica SP5 inverted confocal fluorescence microscope.

\section{Immunofluorescence Staining of BeWo Cells}

BeWo cells were seeded at a density of $2 \times 10^{4}$ cells per well in glass chamber slides (ibidi GmbH, Germany) then incubated for 24 hours. Cells were fixed with cold methanol for 10 minutes and blocked with $1 \%$ BSA, 5\% goat serum, and 0.1\% Tween-20 in PBS for 1 hour at room temperature. Next, cells were incubated at $4^{\circ} \mathrm{C}$ overnight with primary antibodies in humidified chambers. 1:100 dilutions of primary rabbit anti-human TrkB antibodies (Abcam, cat\#: ab18987) and p75NTR antibodies (Abcam, cat\#52987) were used. Anti-rabbit IgG antibodies served as a negative control ( $\mathrm{R} \& \mathrm{D}$ system, Minneapolis, MN). 1:300 dilutions of goat anti-rabbit secondary antibodies and Alexa Fluo 594 (Life Technologies, Carlsbad, CA) were used. F-actin was stained using fluorescein Phalloidin (Invitrogen, cat\# F432) at 1:300 dilution. Nuclei were stained using NucBlue Fixed Cell ReadyProbes Reagent (DAPI, Invitrogen). Slides were mounted using ProLong Diamond Antifade Mountant (Invitrogen) and examined with a Leica SP5 inverted confocal fluorescence microscope.

\section{Cell Viability Assay}

BeWo cells were seeded at a density of $1 \times 10^{4}$ cells per well in 96well plates and incubated for 24 hours. The cells were then treated with each individual PFAS compound at 0, 0.01, 0.1, 1, 10 $\mu \mathrm{M}$ or a PFAS mixture (Table 1 ) at $1: 1,1: 10,1: 50,1: 100$ dilutions 
in quadruplicate for 24 hours. Cell viability was measured using the CellTiter $96^{\circledR}$ AQueous One Solution Cell Proliferation Assay kit as instructed by the manufacturer instructions (G5421; Promega, Madison, WI). The optical density at $490 \mathrm{~nm}$ (OD490) was used to quantitatively compare cell viability between treatments after incubating the cells with MTS reagents for 4 hours. These experiments were repeated five times $(\mathrm{N}=5)$.

\section{Western Blot}

To harvest cell lysates after treatment, we used RIPA buffer (Sigma Aldrich, St. Louis, MO) with the complete mini-protease inhibitor cocktail (Roche, Mannheim, Germany). Protein concentrations were determined with the Bradford assay (BioRad Laboratories, Hercules, CA). $25 \mu \mathrm{g}$ of total protein samples were loaded onto $10 \%$ sodium dodecyl sulfate polyacrylamide gels, separated, and transferred to a polyvinylidene difluoride membrane. The membranes were blocked with $5 \%$ milk in TrisBuffered Saline and Tween-20 (TBST) buffer. Membranes were probed in blocking buffer at $4^{\circ} \mathrm{C}$ with primary antibodies overnight. The following primary antibodies were used in the experiments: rabbit anti-human TrkB antibody (Abcam, cat\#: ab18987), phosphor-TrkB (Tyr816) antibody (Cell Signaling Technology, cat\#4168), and rabbit anti-human pro-BDNF antibody (Invitrogen, cat\# PA1-18360) at 1:1000 dilution; rabbit anti-human GAPDH antibody at 1:20 000 dilution. The secondary antibody was diluted at a ratio of 1:2000. To visualize and photograph the membranes, we used the ChemiDoc MP
Imaging System with Image Lab Software (Bio-Rad, Berkeley, CA). Band intensity was quantified with ImageJ (NIH, Bethesda, MD). Data were normalized to the internal control (GAPDH) and are presented as ratios. Experiments were repeated four times $(\mathrm{N}=4)$.

\section{Statistical Analysis}

Data are presented as means \pm SD. Multiple comparisons between treatments were performed with a one-way ANOVA and the post-hoc Dunnett's test using GraphPad Prism 6.0 (La Jolla, CA). Results from treatment groups are compared to unexposed control cells. A p-value smaller than 0.05 is considered statistically significant.

\section{RESULTS}

\section{Localization of BDNF Receptors in Placental Tissues}

Syndican-1 (SDC-1), a biomarker for syncytiotrophoblast (STB) was stained green on their epical membrane, TrkB and $\mathrm{p} 75^{\mathrm{NTR}}$ receptors were stained red, and nuclei were stained blue (Figure 1). In the first trimester villous placenta, both TrkB and $\mathrm{p} 75^{\mathrm{NTR}}$ staining were most pronounced in the STB and cytotrophoblast cells (CTBs) (Figure 1A). Staining was more intense in the STB compared to the CTBs for the p75 ${ }^{\mathrm{NTR}}$. Spot staining was observed in placental villous stroma tissue for the p $75^{\mathrm{NTR}}$ and TrkB.

\section{A}
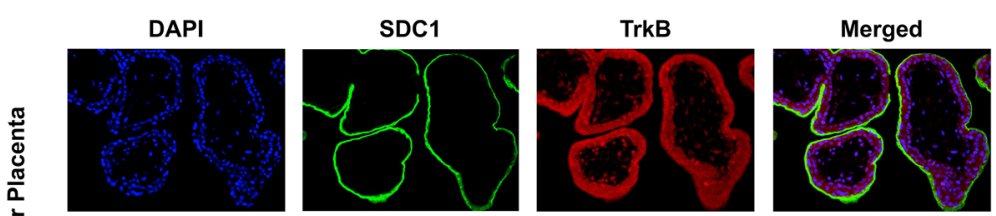

DAPI

SDC1
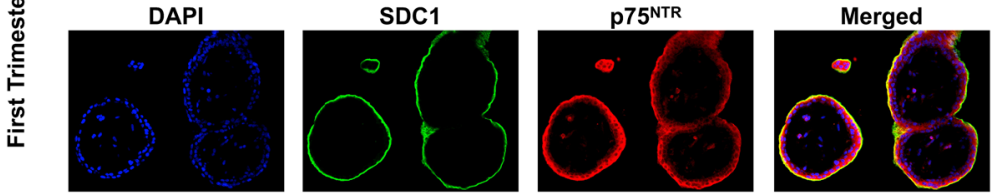

B
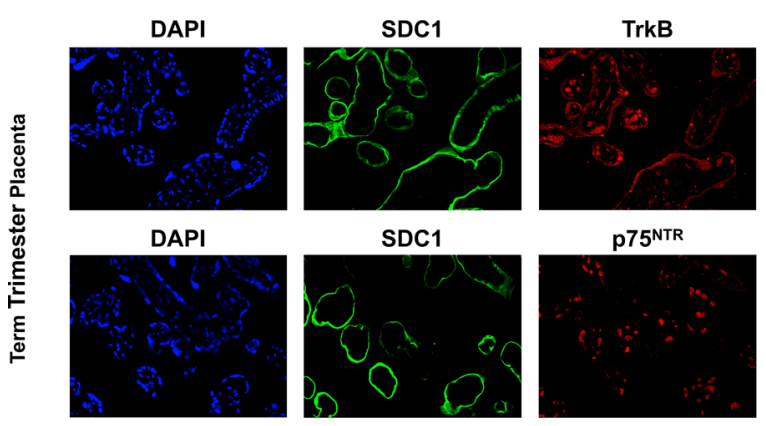

Merged

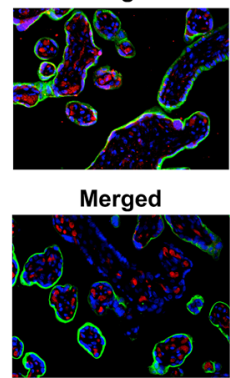

FIGURE 1 | Expression of BDNF receptors in human placental tissues. (A) Representative confocal immunofluorescence staining images of showing DAPI (blue) and SDC1 (a syncytiotrophoblast biomarker, green) along with TrkB (red) and p75 NTR (red) receptors in the first trimester placenta. (B) Confocal immunofluorescence staining images showing DAPI, SDC1, TrkB, and $\mathrm{p} 75^{\mathrm{NTR}}$ in the term placenta. 
In term villous placenta, $\operatorname{TrkB}$ and $\mathrm{p} 75^{\mathrm{NTR}}$ receptors were primarily observed in the placental villous stroma distinguished it from the first trimester placenta (Figure 1B). TrkB receptor staining in STB was reduced, while $\mathrm{p} 75^{\mathrm{NTR}}$ receptor staining was negative. Given these results and our focus on trophoblast cells, TrkB receptors in BeWo cells were examined further in this study.

\section{Localization and Expression of TrkB in BeWo Cells}

The presence of TrkB receptors in placental BeWo cells was evaluated through immunofluorescence staining. BeWo cells were cultured with and without forskolin treatments. Forskolin treatment was administered to induce fusion of the cells, modeling the villous trophoblast syncytialization (63). F-actin staining distinguished individual BeWo cells before forskolin treatment and diminished in fused cells after treatment. TrkB receptors appeared to be localized in the nuclei, and some appeared to be translocated into the perinuclear region after forskolin-induced fusion. Representative images of TrkB staining in BeWo cells are presented in Figure 2.

\section{PFAS-Induced Disruption of the BDNF Pathway in BeWo Cells}

After confirming the presence of TrkB receptors, we examined the effects of PFAS exposure on BDNF production and the ratio of phosphorylated TrkB to total TrkB in BeWo cells with and without forskolin treatment by Western blots. First, the MTS cell viability assay confirmed that the doses used in this study did not cause cell death. Next, we screened the phosphorylation sites, Tyr516, Tyr706/707, and Tyr816 of TrkB receptors in BeWo cells. The phospho-TrkB (Tyr816) was widely detected in these cells with and without forskolin treatment. Finally, Western blot results demonstrated that exposure to PFOS, PFOA, PFBS, and the six-PFAS mixture did not significantly alter BDNF production or activation of $\operatorname{TrkB}$, manifested by the constant ratio of phospho-TrkB (Tyr816) to total TrkB at any given dose (Figures 3-7). Although BDNF production was not changed by PFNA exposures, the ratio of phospho-TrkB (Tyr816) to total TrkB was significantly higher in forskolin-treated BeWo cells exposed to $10 \mu \mathrm{M}$ and $1 \mu \mathrm{M}$ of PFNA than in unexposed forskolin-treated BeWo cells ( $P=0.02$; Figure 3). The same trend was observed in BeWo cells without forskolin treatment but was not significant (Figure 3).

\section{DISCUSSION}

This study investigates the BDNF signaling pathway in placental cells and how it is affected by exposure to various PFAS compounds and a PFAS mixture mimicking residents' blood levels in Pittsboro, North Carolina, USA. Confocal immunofluorescence staining results show that TrkB receptors are present in trophoblasts in the first trimester and term placental villi. Similar expression of $\mathrm{p} 75^{\mathrm{NTR}}$ receptors was observed in first trimester placental tissues. At term, however, $\mathrm{p} 75^{\mathrm{NTR}}$ receptors were primarily located in the placental villous stroma. Immunofluorescence staining results reveal that TrkB receptors are localized to the nuclear and perinuclear regions in BeWo cells. Western blot results indicate that TrkB receptors are activated in BeWo cells by phosphorylation at the Tyr816 site. Additionally, Western blots demonstrate that PFNA exposure at $1 \mu \mathrm{M}$ and $10 \mu \mathrm{M}$ doses increased the ratio of phospho-TrkB (Tyr816) to total TrkB. Exposure to other PFAS compounds (PFOS, PFOA, PFBS) and the PFAS mixture did not significantly alter BDNF signaling, as evidenced by unchanged levels of BDNF and phospho-TrkB. Thus, the impacts of PFAS exposure on fetal neurodevelopment previously observed in cohort studies (14-23) do not necessarily occur via the placental BDNF pathway.

Although BDNF signaling has been extensively studied in neuronal tissues and cells, little is known about this pathway in

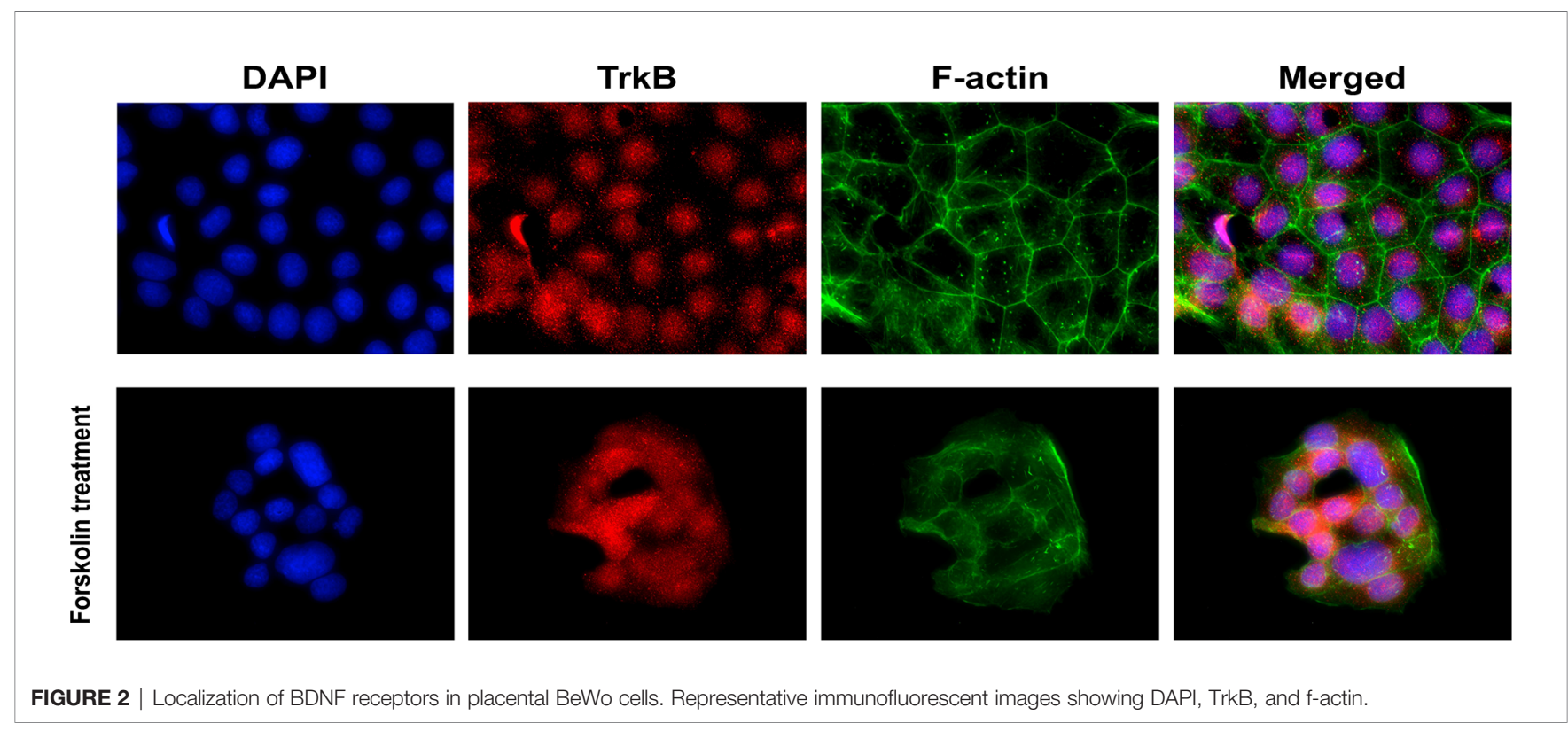


A
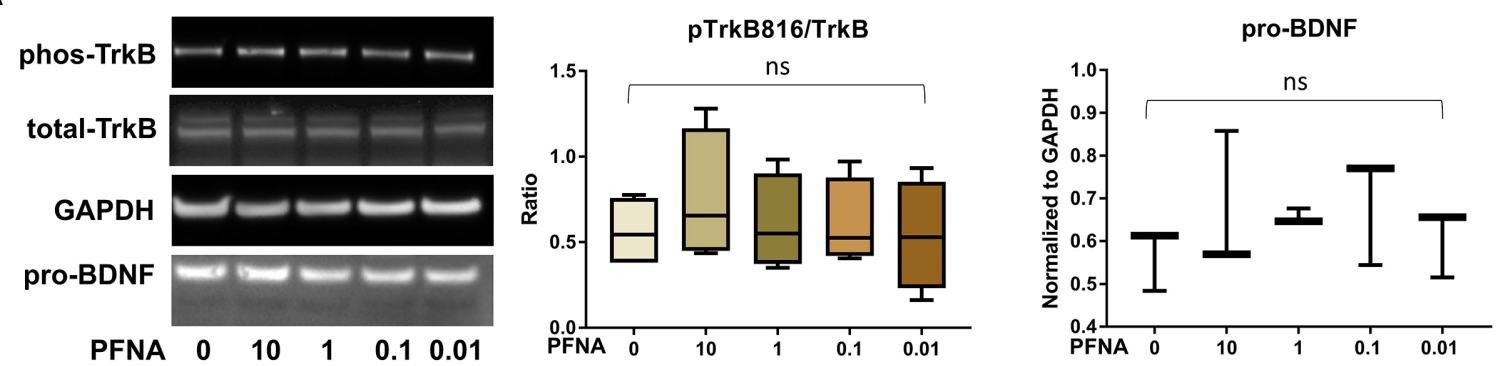

B
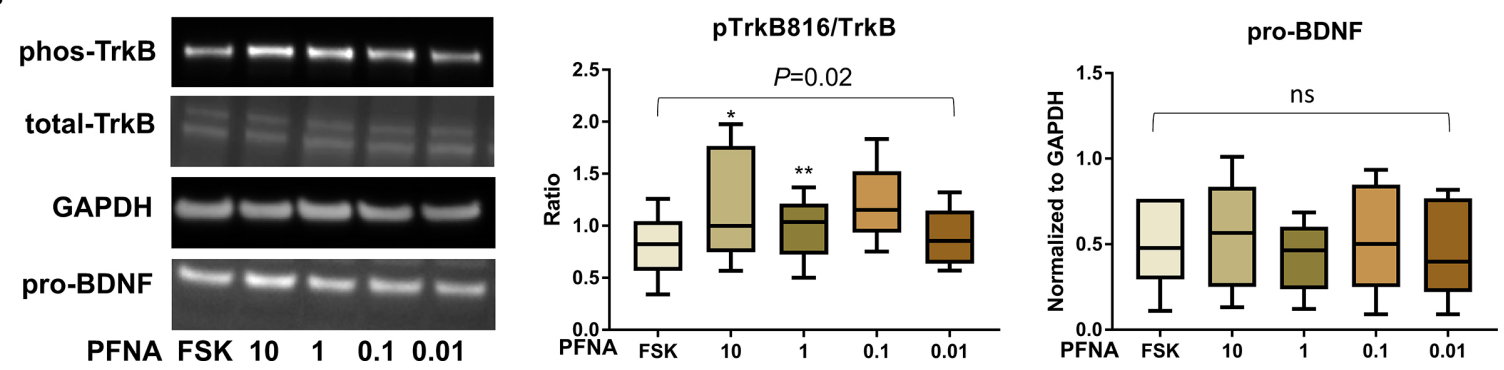

FIGURE 3 | Altered TrkB phosphorylation at high concentrations of PFNA. (A) Representative Western blot images of phos-TrkB, total-TrkB, GAPDH, and proBDNF in BeWo cells without forskolin (FSK) treatment exposed to PFNA (0, 0.01, 0.1, 1, and $10 \mu \mathrm{M}$ ) and box plots for densitometry analysis; (B) Representative Western blot images of phos-TrkB, total-TrkB, GAPDH, and pro-BDNF in BeWo cells with FSK treatment exposed to PFNA $(0,0.01,0.1,1$, and 10 $\mu \mathrm{M})$ and box plots for densitometry analysis. ns indicates differences in protein levels were not significant. pTrkB816 represents for phosphorylation of TrkB at Tyr816 residue. ${ }^{\star} \mathrm{P}<0.05{ }^{\star \star} \mathrm{P}<0.01$ compared to unexposed forskolin-treated cells.

A

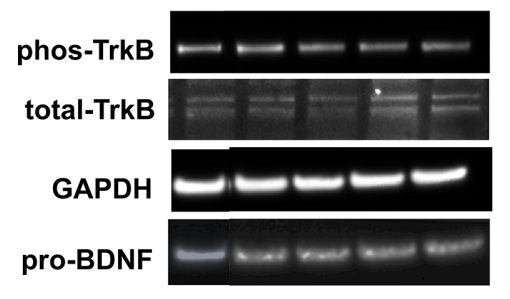

PFOS $\quad 0 \quad 10 \quad 1 \quad 0.1 \quad 0.01$

B

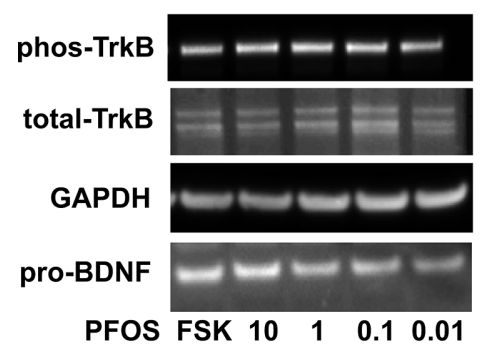

pTrkB816/TrkB

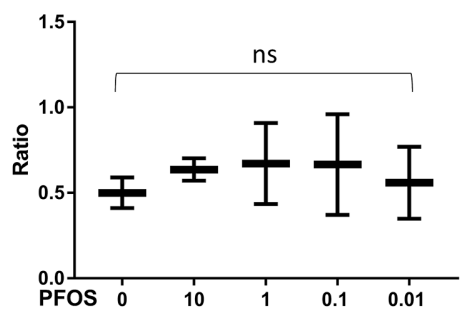

pTrkB816/TrkB

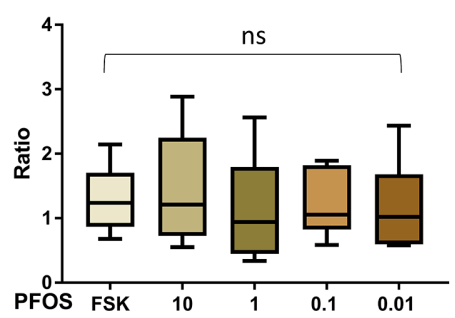

pro-BDNF

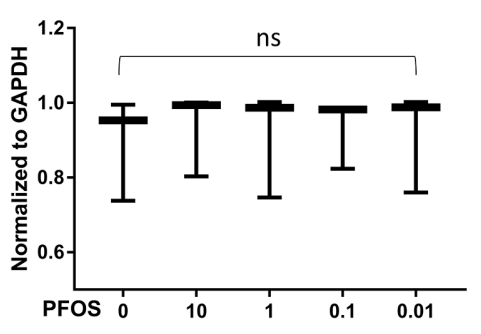

pro-BDNF

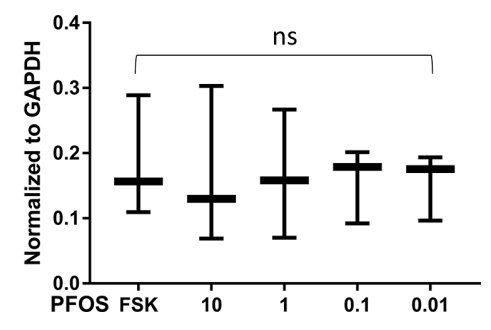

FIGURE 4 | PFOS exposure did not significantly disrupt the BDNF-TrkB pathway. (A) Representative Western blot images of phos-TrkB, total-TrkB, GAPDH, and pro-BDNF in BeWo cells without forskolin (FSK) treatment exposed to PFOS $(0,0.01,0.1,1$, and $10 \mu \mathrm{M})$ and box plots for densitometry analysis; (B) Representative Western blot images of phos-TrkB, total-TrkB, GAPDH, and pro-BDNF in BeWo cells with FSK treatment exposed to PFOS $(0,0.01,0.1,1$, and $10 \mu \mathrm{M})$ and box plots for densitometry analysis. ns indicates differences in protein levels were not significant. pTrkB816 represents for phosphorylation of TrkB at Tyr816 residue. 


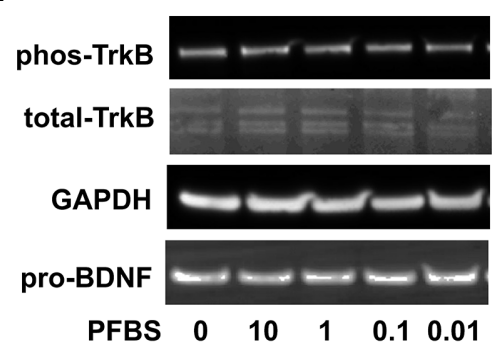

B

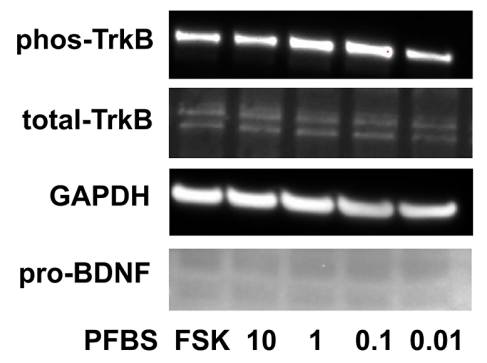

pTrkB816/TrkB
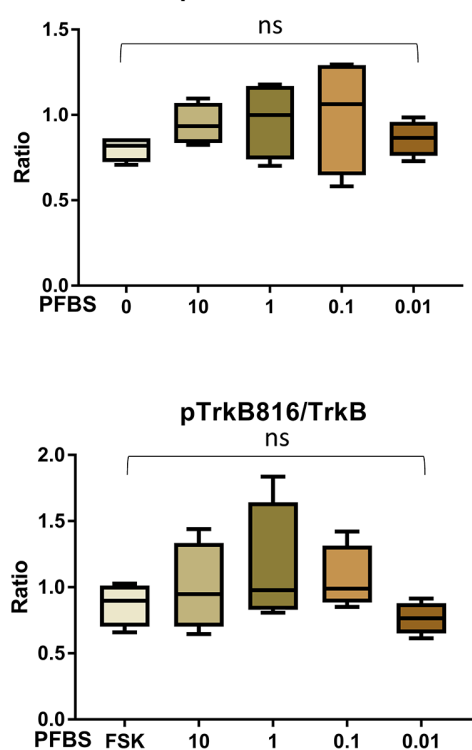

pro-BDNF

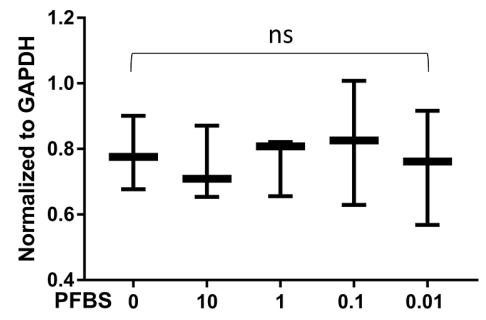

pro-BDNF

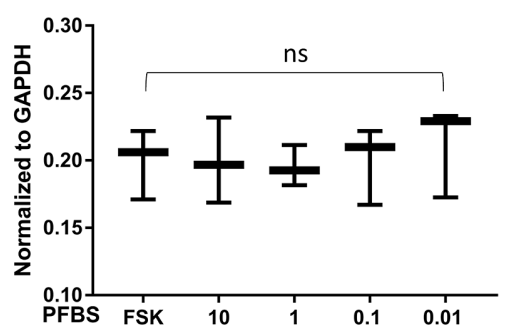

FIGURE 5 | PFBS exposure did not significantly disrupt the BDNF-TrkB pathway. (A) Representative Western blot images of phos-TrkB, total-TrkB, GAPDH, and pro-BDNF in BeWo cells without forskolin (FSK) treatment exposed to PFBS $(0,0.01,0.1,1$, and $10 \mu \mathrm{M})$ and box plots for densitometry analysis; (B) Representative Western blot images of phos-TrkB, total-TrkB, GAPDH, and pro-BDNF in BeWo cells with FSK treatment exposed to PFBS $(0,0.01,0.1,1$, and $10 \mu \mathrm{M})$ and box plots for densitometry analysis. ns indicates differences in protein levels were not significant. pTrkB816 represents for phosphorylation of TrkB at Tyr816 residue.

A

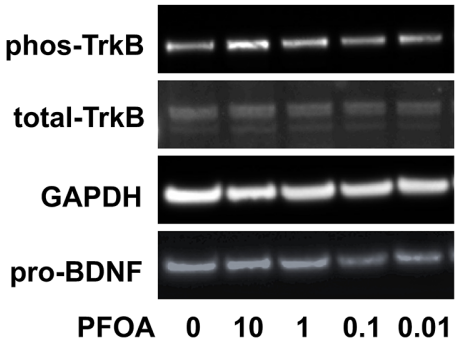

B

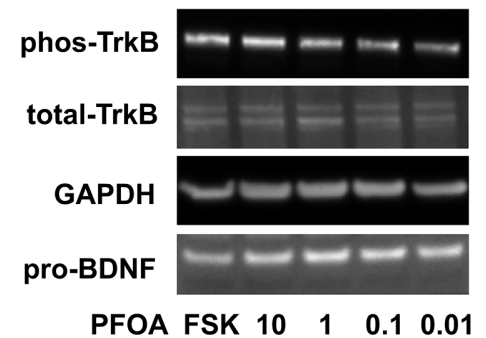

pTrkB816/TrkB

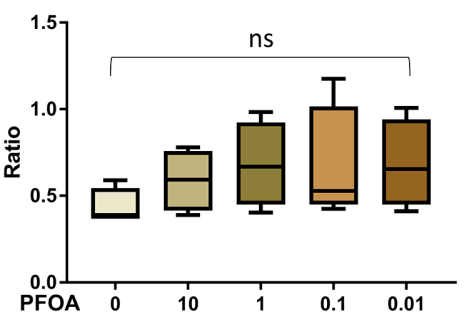

pTrkB816/TrkB

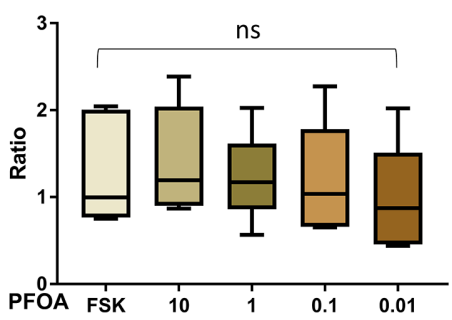

pro-BDNF

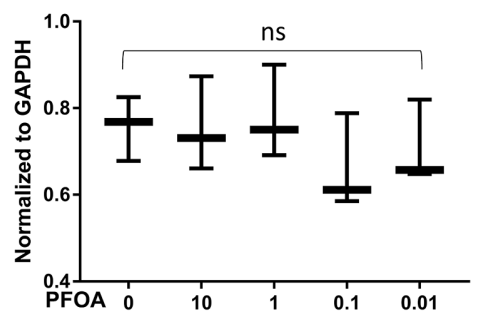

pro-BDNF

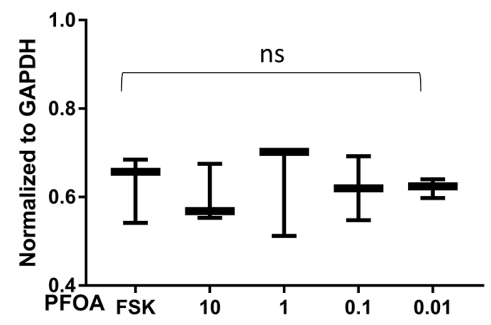

FIGURE 6 | PFOA exposure did not significantly disrupt the BDNF-TrkB pathway. (A) Representative Western blot images of phos-TrkB, total-TrkB, GAPDH, and pro-BDNF in BeWo cells without forskolin (FSK) treatment exposed to PFOA (0, 0.01, 0.1, 1, and $10 \mu \mathrm{M})$ and box plots for densitometry analysis; (B) Representative Western blot images of phos-TrkB, total-TrkB, GAPDH, and pro-BDNF in BeWo cells with FSK treatment exposed to PFOA $(0,0.01,0.1,1$, and $10 \mu \mathrm{M})$ and box plots for densitometry analysis. ns indicates differences in protein levels were not significant. pTrkB816 represents for phosphorylation of TrkB at Tyr816 residue. 


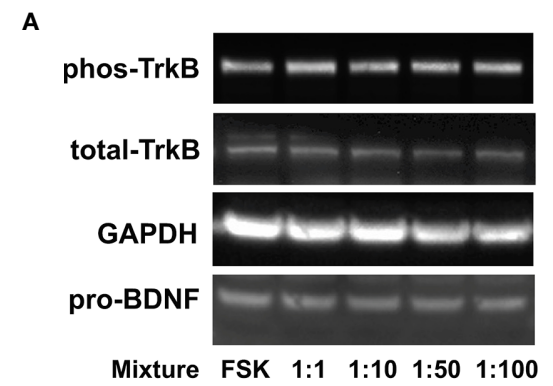

B

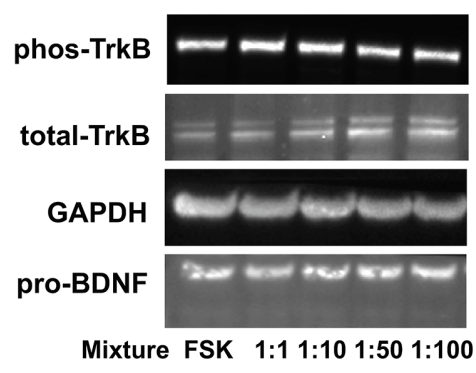

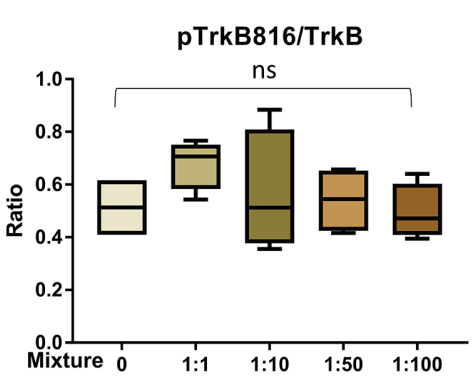

pTrkB816/TrkB

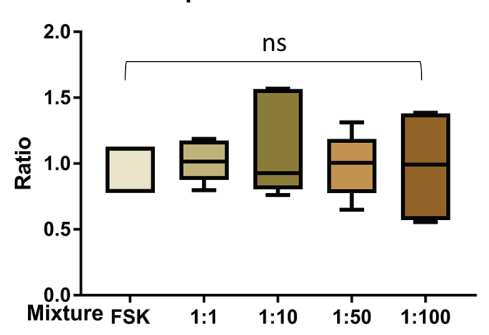

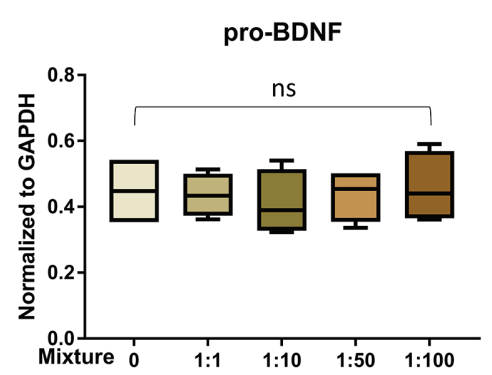

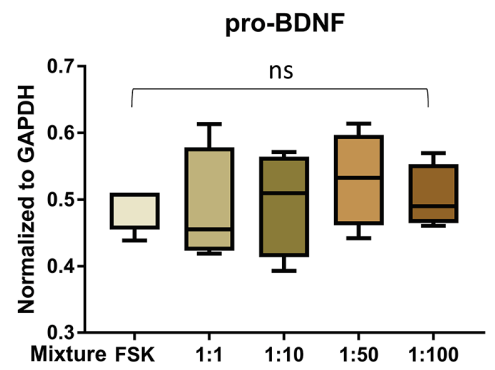

FIGURE 7 | PFAS mixture exposure (detailed in Table 1) did not significantly disrupt the BDNF-TrkB pathway. (A) Representative Western blot images of phosTrkB, total-TrkB, GAPDH, and pro-BDNF in BeWo cells without forskolin (FSK) treatment exposed to mixture dilutions (0, 1:1, 1:10, 1:50, 1:100) and box plots for densitometry analysis; (B) Representative Western blot images of phos-TrkB, total-TrkB, GAPDH, and pro-BDNF in BeWo cells with FSK treatment exposed to mixture dilutions $(0,1: 1,1: 10,1: 50,1: 100)$ and box plots for densitometry analysis. ns indicates differences in protein levels were not significant. pTrkB816 represents for phosphorylation of TrkB at Tyr816 residue.

gestational tissues. The current study further characterizes the BDNF pathway in placental tissues. BDNF is first synthesized as a precursor protein, prepro-BDNF, which is converted into pro$\mathrm{BDNF}$ by removal of the signal peptide (64). Once the protein is secreted, pro-BDNF is converted to mature BDNF (mBDNF) through proteolytic cleavage by furin and other proprotein convertases (65). We were able to detect pro-BDNF by Western blots in BeWo cell lysates. However, mBDNF levels were close to the limits of detection in BeWo cell culture media, which could be due to limited pro-BDNF secretion or cleavage in our current culture condition. mBDNF is preferentially released via a tightly controlled pathway driven by activity-dependent depolarization and $\mathrm{Ca}^{2+}$ entry (66). BDNF binds to specific receptors and regulates distinct biological functions. The BDNF receptors in this study were localized in discrete placental domains, indicating that BDNF exhibits distinct functions in different placental cells. BDNF binding to TrkB results in TrkB activation and autophosphorylation at Tyr sites (67). The activated $\operatorname{TrkB}$ receptors can induce an array of intracellular signaling cascades (43). TrkB receptor activation at the Tyr490 and Tyr515 residues regulates MAPK/ERK kinases and the PI3K/Akt pathway (68). Both of these pathways activate transcription factors (CREB and $\mathrm{C}-\mathrm{myc}$ ) which trigger neurotrophic functions of cell survival, growth, and differentiation (68). Phosphorylation of TrkB receptors at the Tyr816 site activates phospholipase C $\gamma(\operatorname{PLC} \gamma)(68,69)$. The phosphorylation of Tyr706/707 sites can lead to the transphosphorylation of Tyr515 and Tyr816 residues $(69,70)$.
These signaling pathways support many aspects of growth and development such as cell survival, synaptic structure, and synaptic plasticity $(43,59)$. In BeWo cell cultures, the phosphorylation of the $\operatorname{TrkB}$ receptor at its Tyr816 residue was robustly detected, while its Tyr515 and Tyr707 residues were seldom observed.

Expression of neurotrophins like BDNF is susceptible to change in response to perturbations in the maternal environment (40). Exposure to environmental pollutants is a maternal challenge that may affect BDNF expression and signaling in offspring. In rodents, prenatal stress can lead to decreased BDNF expression in offspring from weaning to adulthood (54). Moreover, mouse prenatal exposure to synthetic organic compounds such as bisphenol A (BPA) can induce lasting DNA methylations in transcriptionally relevant BDNF regions (54). Other studies have observed altered cord blood concentrations in humans following acute BPA exposure (35). Given these previous findings, the continued investigation of PFAS-induced BDNF pathway disruptions is imperative. Li et al. found increased $\operatorname{TrkB}$ expression in response to $10 \mu \mathrm{M}$ doses of PFOS in human neuroblastoma cells (58). However, this observation was a proposed compensatory response to a simultaneous PFOS-related decrease in BDNF protein levels, which was seen in other reports $(58,59)$. Generally, the PFAS mixture and individual PFAS compounds did not significantly regulate the BDNF pathway in BeWo cells in this study. The phosphorylation of TrkB at the Tyr816 site was only increased by PFNA exposure at 1 and $10 \mu \mathrm{M}$ levels. We speculate that the 
activation of TrkB receptors is a secondary effect of PFNA exposure on these cells because the protein levels of pro-BDNF were not altered by PFNA exposure and mBDNF was not detected. Further, the activation of TrkB receptors can be triggered by other pathways or ligands unrelated to BDNF (71, 72). Additional studies are needed to investigate the mechanism by which PFNA induces changes in the BDNF signaling pathway and what other neurohormonal pathways could be disrupted by PFAS in both the placenta and fetal brain.

The present study has several limitations. First, the PFAS mixture in this study was based on blood concentrations of Pittsboro residents who were not pregnant. Maternal and placental blood levels of PFAS are unknown at this time. Second, the timeline and dosing allowed us to study the effects of acute exposures but preclude us from drawing conclusions about chronic low-level exposure. Third, our findings are limited to in vitro observations. However, we found a strong correlation between in vitro (BeWo cells) and in vivo (mice placenta and fetal brain tissues) observations of the BDNF pathway upon PM2.5 exposure [unpublished data]. Finally, our findings are based on a single cell model due to the limited availability of STB cell models. JAR, JEG-3-other in vitro models of the trophoblast barrier-were unsuitable for this study because they fail to undergo substantial syncytial fusion $(73,74)$.

This study is the first to localize p75 and TrkB receptors in the human placenta at different stages of gestation and in placental cells originating from choriocarcinoma (BeWo cells). Three individually tested PFAS compounds (PFOA, PFOS, PFBS) and a six-PFAS mixture mimicking residential exposure in Pittsboro, North Carolina, did not induce increased TrkB phosphorylation or alter pro-BDNF levels. Additionally, our results showed that in cells exposed to high concentrations of PFNA, phosphorylation of TrkB receptors increased while proBDNF levels remained stable. Although BDNF plays a critical role in brain development throughout all stages of life, it is unlikely to be primarily responsible for the observed neurodevelopmental consequences associated with in utero PFAS exposure. Additional investigation is required to understand whether adverse effects arise via an alternative

\section{REFERENCES}

1. Rappazzo KM, Coffman E, Hines EP. Exposure to Perfluorinated Alkyl Substances and Health Outcomes in Children: A Systematic Review of the Epidemiologic Literature. Int J Environ Res Public Health (2017) 14(7):1-22. doi: 10.3390/ijerph14070691

2. Birnbaum ,LS. Hearing on "The Federal Role in the Toxic PFAS Chemical Crisis" Testimony. Senate Committee on Homeland Security and Governmental Affairs Subcommittee on Federal Spending Oversight and Emergency Management (2018). https://doi.org/10.1093/.

3. Pelch KE, Reade A, Wolffe TAM, Kwiatkowski CF. PFAS Health Effects Database: Protocol for a Systematic Evidence Map. Environ Inter (2019) 130:104851. 10.1016/j.envint.2019.05.045

4. Houde M, Martin JW, Letcher RJ, Solomon KR, Muir DCG. Biological Monitoring of Polyfluoroalkyl Substances: A Review. Environ Sci Technol (2006) 40(11):3463-73. doi: 10.1021/es052580b

5. Liew Z, Goudarzi H, Oulhote Y. Developmental Exposures to Perfluoroalkyl Substances (PFASs): An Update of Associated Health Outcomes. Curr Environ Health Rep (2018) 5(1):1-19. doi: 10.1007/s40572-018-0173-4 placental pathway or are enacted directly on the fetus. These findings contribute to an improved understanding of the understudied BDNF signaling pathway in the gestational tissues and how the pathway is altered by PFAS exposure.

\section{DATA AVAILABILITY STATEMENT}

The raw data supporting the conclusions of this article will be made available by the authors, without undue reservation.

\section{ETHICS STATEMENT}

The studies involving human participants were reviewed and approved by the Ethics Committees of Xinhua Hospital affiliated with Shanghai Jiao Tong University School of Medicine and the Duke University Institutional Review Board. The patients/ participants provided their written informed consent to participate in this study.

\section{AUTHOR CONTRIBUTIONS}

MM drafted the manuscript. SL performed research and data analysis. JZ contributed to the study design and drafting the manuscript. LF designed research, performed experiments and data analysis, and revised the manuscript. All authors contributed to the article and approved the submitted version.

\section{FUNDING}

This work was supported by the Fogarty International Center of the National Institutes of Health under Award Number 1K01TW010828-01 (PI: LF). The funder had no role in study design, data collection and analysis, decision to publish, or preparation of the manuscript.

6. Fromme H, Tittlemier SA, Völkel W, Wilhelm M, Twardella D Perfluorinated Compounds - Exposure Assessment for the General Population in Western Countries. Int J Hyg Environ Health (2009) 212 (3):239-70. doi: 10.1016/j.ijheh.2008.04.007

7. Lewis RC, Johns LE, Meeker JD. Serum Biomarkers of Exposure to Perfluoroalkyl Substances in Relation to Serum Testosterone and Measures of Thyroid Function Among Adults and Adolescents From NHANES 2011-2012. Int J Environ Res Public Health (2015) 12(6):6098-114. doi: 10.3390/ijerph120606098

8. Calafat AM, Kuklenyik Z, Reidy JA, Caudill SP, Tully JS, Needham LL. Serum Concentrations of 11 Polyfluoroalkyl Compounds in the U.S. Population: Data From the National Health and Nutrition Examination Survey (NHANES) 19992000. Environ Sci Technol (2007) 41(7):2237-42. doi: 10.1021/es062686m

9. Khalil N, Chen A, Lee M, Czerwinski SA, Ebert JR, De Witt JC, et al. Association of Perfluoroalkyl Substances, Bone Mineral Density, and Osteoporosis in the U.S. Population in NHANES 2009-2010. Environ Health Perspect (2016) 124(1):81-7. doi: 10.1289/ehp.1307909

10. Agency for Toxic Substances and Disease Registry. Toxicological Profile for Perfluoroalkyls. Oxid Med Cell Longev (2018) 1-882. 
11. Austin ME, Kasturi BS, Barber M, Kannan K, MohanKumar PS, MohanKumar SMJ. Neuroendocrine Effects of Perflurooactane Sulfonate in Rats. Environ Health Perspect (2003) 11(12):1485-9. doi: 10.1289/ehp.6128

12. Apelberg BJ, Goldman LR, Calafat AM, Herbstman JB, Kuklenyik Z, Heidler J, et al. Determinants of Fetal Exposure to Polyfluoroalkyl Compounds in Baltimore, Maryland. Environ Sci Technol (2007) 41(11):3891-7. doi: 10.1021/es0700911

13. Kärrman A, Ericson I, VanBavel B, Ola Darnerud P, Aune M, Glynn A, et al. Exposure of Perfluorinated Chemicals Through Lactation: Levels of Matched Human Milk and Serum and a Temporal Trend, 1996-2004, in Sweden. Environ Health Perspect (2007) 115(2):226-30. doi: 10.1289/ehp.9491

14. Chen MH, Ha EH, Liao HF, Jeng SF, Su YN, Wen TW, et al. Perfluorinated Compound Levels in Cord Blood and Neurodevelopment at 2 Years of Age. Epidemiology (2013) 24(6):800-8. doi: 10.1097/EDE.0b013 e3182a6dd46

15. Harris MH, Oken E, Rifas-Shiman SL, Calafat AM, Ye X, Bellinger DC, et al. Prenatal and Childhood Exposure to Per- and Polyfluoroalkyl Substances (PFASs) and Child Cognition. Environ Int (2018) 115:358-69. doi: 10.1016/ j.envint.2018.03.025

16. Wang Y, Rogan WJ, Chen HY, Chen PC, Su PH, Chen HY, et al. Prenatal Exposure to Perfluroalkyl Substances and Children's IQ: The Taiwan Maternal and Infant Cohort Study. Int J Hyg Environ Health (2015) 218 (7):639-44. doi: 10.1016/j.ijheh.2015.07.002

17. Høyer BB, Bonde JP, Tøttenborg SS, Ramlau-Hansen CH, Lindh C, Pedersen HS, et al. Exposure to Perfluoroalkyl Substances During Pregnancy and Child Behaviour at 5 to 9 Years of Age. Horm Behav (2018) 101:105-12. doi: 10.1016/j.yhbeh.2017.11.007

18. Luo J, Xiao J, Gao Y, Ramlau-Hansen CH, Toft G, Li J, et al. Prenatal Exposure to Perfluoroalkyl Substances and Behavioral Difficulties in Childhood at 7 and 11 Years. Environ Res (2020) 191:110111. doi: 10.1289/isee.2020.virtual.P-0872

19. Vuong AM, Webster GM, Yolton K, Calafat AM, Muckle G, Lanphear BP, et al. Prenatal Exposure to Per- and Polyfluoroalkyl Substances (PFAS) and Neurobehavior in US Children Through 8 Years of Age: The HOME Study. Environ Res (2021) 195:110825. doi: 10.1016/j.envres.2021.110825

20. Vuong AM, Yolton K, Wang Z, Xie C, Webster GM, Ye X, et al. Childhood Perfluoroalkyl Substance Exposure and Executive Function in Children at 8 Years. Environ Int (2018) 119:212-9. doi: 10.1016/j.envint.2018.06.028

21. Niu J, Liang H, Tian Y, Yuan W, Xiao H, Hu H, et al. Prenatal Plasma Concentrations of Perfluoroalkyl and Polyfluoroalkyl Substances and Neuropsychological Development in Children at Four Years of Age. Environ Health (2019) 18(1):53. doi: 10.1186/s12940-019-0493-3

22. Hoffman K, Webster TF, Weisskopf MG, Weinberg J, Vieira VM. Exposure to Polyfluoroalkyl Chemicals and Attention Deficit/Hyperactivity Disorder in U.S. Children 12-15 Years of Age. Environ Health Perspect (2010) 118 (12):1762-7. doi: 10.1289/ehp.1001898

23. Lien GW, Huang CC, Shiu JS, Chen MH, Hsieh WS, Guo YL, et al. Perfluoroalkyl Substances in Cord Blood and Attention Deficit/ Hyperactivity Disorder Symptoms in Seven-Year-Old Children. Chemosphere (2016) 156:118-27. doi: 10.1016/j.chemosphere.2016.04.102

24. Forns J, Verner MA, Iszatt N, Nowack N, Bach CC, Vrijheid M, et al. Early Life Exposure to Perfluoroalkyl Substances (PFAS) and ADHD: A MetaAnalysis of Nine European Population-Based Studies. Environ Health Perspect (2020) 128(5):57002. doi: 10.1289/EHP5444

25. Liew Z, Ritz B, Bach CC, Asarnow RF, Bech BH, Nohr EA, et al. Prenatal Exposure to Perfluoroalkyl Substances and IQ Scores at Age 5; A Study in the Danish National Birth Cohort. Environ Health Perspect (2018) 126(6):067004. doi: 10.1289/EHP2754

26. Fei C, Olsen J. Prenatal Exposure to Perfluorinated Chemicals and Behavioral or Coordination Problems at Age 7 Years. Environ Health Perspect (2011) 119 (4):573-8. doi: 10.1289/ehp.1002026

27. Strøm M, Hansen S, Olsen SF, Haug LS, Rantakokko P, Kiviranta H, et al. Persistent Organic Pollutants Measured in Maternal Serum and Offspring Neurodevelopmental Outcomes - A Prospective Study With Long-Term Follow-Up. Environ Int (2014) 68:41-8. doi: 10.1016/j.envint.2014.03.002

28. Forns J, Iszatt N, White RA, Mandal S, Sabaredzovic A, Lamoree M, et al. Perfluoroalkyl Substances Measured in Breast Milk and Child Neuropsychological Development in a Norwegian Birth Cohort Study. Environ Int (2015) 83:176-82. doi: 10.1016/j.envint.2015.06.013
29. Vuong AM, Braun JM, Yolton K, Wang Z, Xie C, Webster GM, et al. Prenatal and Childhood Exposure to Perfluoroalkyl Substances (PFAS) and Measures of Attention, Impulse Control, and Visual Spatial Abilities. Environ Int (2018) 119:413-20. doi: 10.1016/j.envint.2018.07.013

30. Zheleznyakova GY, Cao H, Schiöth HB. BDNF DNA Methylation Changes as a Biomarker of Psychiatric Disorders: Literature Review and Open Access Database Analysis. Behav Brain Funct (2016) 12(1):17. doi: 10.1186/s12993016-0101-4

31. De La Cruz-Morcillo MA, Berger J, Sánchez-Prieto R, Saada S, Naves T, Guillaudeau A, et al. P75 Neurotrophin Receptor and Pro-BDNF Promote Cell Survival and Migration in Clear Cell Renal Cell Carcinoma. Oncotarget (2016) 7(23):34480-97. doi: 10.18632/oncotarget.8911

32. Mayeur S, Silhol M, Moitrot E, Barbaux S, Breton C, Gabory A, et al. Placental BDNF/TrkB Signaling System is Modulated by Fetal Growth Disturbances in Rat and Human. Placenta (2010) 31(9):785-91. doi: 10.1016/ j.placenta.2010.06.008

33. Tsankova NM, Berton O, Renthal W, Kumar A, Neve RL, Nestler EJ. Sustained Hippocampal Chromatin Regulation in a Mouse Model of Depression and Antidepressant Action. Nat Neurosci (2006) 9:519-25. doi: $10.1038 / \mathrm{nn} 1659$

34. Jha S, Dong B, Sakata K. Enriched Environment Treatment Reverses Depression-Like Behavior and Restores Reduced Hippocampal Neurogenesis and Protein Levels of Brain-Derived Neurotrophic Factor in Mice Lacking its Expression Through Promoter IV. Transl Psychiatry (2011) 1484(1):9-31. doi: 10.1038/tp.2011.33

35. Kundakovic M, Gudsnuk K, Herbstman JB, Tang D, Perera FP, Champagne FA. DNA Methylation of BDNF as a Biomarker of Early-Life Adversity. Proc Natl Acad Sci U S A (2015) 112(22):6807-13. doi: 10.1073/pnas.1408355111

36. Notaras M, Hill R, Van den Buuse M. A Role for the BDNF Gene Val66Met Polymorphism in Schizophrenia? A Comprehensive Review. Neurosci Biobehav Rev (2015) 51:15-30. doi: 10.1016/j.neubiorev.2014.12.016

37. Kang H-J, Kim J-M, Lee J-Y, Kim S-Y, Bae K-Y, Kim S-W, et al. BDNF Promoter Methylation and Suicidal Behavior in Depressive Patients. J Affect Disord (2013) 151(2):679-85. doi: 10.1016/j.jad.2013.08.001

38. Lee Y, Lim SW, Kim SY, Chung JW, Kim J, Myung W, et al. Association Between the BDNF Val66Met Polymorphism and Chronicity of Depression. Psychiatry Investig (2013) 10(1):56-61. doi: 10.4306/pi.2013.10.1.56

39. Brooks SJ, Nilsson EK, Jacobsson JA, Stein DJ, Fredriksson R, Lind L, et al. BDNF Polymorphisms are Linked to Poorer Working Memory Performance, Reduced Cerebellar and Hippocampal Volumes and Differences in Prefrontal Cortex in a Swedish Elderly Population. PloS One (2014) 9(1):e82707. doi: 10.1371/journal.pone.0082707

40. Zeltser LM, Leibel RL. Roles of the Placenta in Fetal Brain Development. Proc Natl Acad Sci U S A (2011) 108(38):15667-8. doi: 10.1073/pnas.1112239108

41. Sahay A, Kale A, Joshi S. Role of Neurotrophins in Pregnancy and Offspring Brain Development. Neuropeptides (2020) 83:102075. Churchill Livingstone. doi: 10.1016/j.npep.2020.102075

42. Nikolaou KE, Malamitsi-Puchner A, Boutsikou T, Economou E, Boutsikou M, Puchner K-P, et al. The Varying Patterns of Neurotrophin Changes in the Perinatal Period. Ann N Y Acad Sci (2006) 1092(1):426-33. doi: 10.1196/ annals.1365.041

43. Binder DK, Scharfman HE. Brain-Derived Neurotrophic Factor. Growth Factors (2004) 22(3):123-31. doi: 10.1016/B0-12-341103-3/00037-1

44. Zagrebelsky M, Korte M. Form Follows Function: BDNF and its Involvement in Sculpting the Function and Structure of Synapses. Neuropharmacology (2014) 76:628-38. Pergamon. doi: 10.1016/j.neuropharm.2013.05.029

45. Chao MV, Hempstead BL. P75 and Trk: A Two-Receptor System. Trends Neurosci (1995) 18(7):321-6. doi: 10.1016/0166-2236(95)93922-K

46. Kodomari I, Wada E, Nakamura S, Wada K. Maternal Supply of BDNF to Mouse Fetal Brain Through the Placenta. Neurochem Int (2009) 54(2):95-8. doi: 10.1016/j.neuint.2008.11.005

47. Wada E, Wada K. Bio-Communication Between Mother and Offspring. In: Reproductive and Developmental Toxicology. Elsevier Inc (2011). p. 33-8.

48. Mayeur S, Lukaszewski MA, Breton C, Storme L, Vieau D, Lesage J. Do Neurotrophins Regulate the Feto-Placental Development? Med Hypotheses (2011) 76(5):726-8. doi: 10.1016/j.mehy.2011.02.008

49. Kawamura K, Kawamura N, Kumazawa Y, Kumagai J, Fujimoto T, Tanaka T. Brain-Derived Neurotrophic Factor/Tyrosine Kinase B Signaling Regulates 
Human Trophoblast Growth in an In Vivo Animal Model of Ectopic Pregnancy. Endocrinology (2011) 152(3):1090-100. doi: 10.1210/en.2010-1124

50. Kertes DA, Bhatt SS, Kamin HS, Hughes DA, Rodney NC, Mulligan CJ. BNDF Methylation in Mothers and Newborns is Associated With Maternal Exposure to War Trauma. Clin Epigenet (2017) 9(1):68. doi: 10.1186/s13148-017-0367-x

51. Kermani P, Hempstead B. Brain-Derived Neurotrophic Factor: A Newly Described Mediator of Angiogenesis. Trends Cardiovasc Med (2007) 17 (4):140-3. doi: 10.1016/j.tcm.2007.03.002

52. D'Souza V, Patil V, Pisal H, Randhir K, Joshi A, Mehendale S, et al. Levels of Brain Derived Neurotrophic Factors Across Gestation in Women With Preeclampsia. Int J Dev Neurosci (2014) 37:36-40. doi: 10.1016/ j.ijdevneu.2014.06.008

53. Kawamura K, Kawamura N, Sato W, Fukuda J, Kumagai J, Tanaka T. BrainDerived Neurotrophic Factor Promotes Implantation and Subsequent Placental Development by Stimulating Trophoblast Cell Growth and Survival. Endocrinology (2009) 150(8):3774-82. doi: 10.1210/en.2009-0213

54. Boersma GJ, Lee RS, Cordner ZA, Ewald ER, Purcell RH, Moghadam AA, et al. Prenatal Stress Decreases Bdnf Expression and Increases Methylation of Bdnf Exon IV in Rats. Epigenetics (2013) 9(3):437-47. doi: 10.4161/epi.27558

55. Annunziato KM, Jantzen CE, Gronske MC, Cooper KR. Subtle Morphometric, Behavioral and Gene Expression Effects in Larval Zebrafish Exposed to PFHxA, PFHxS and 6:2 FTOH. Aquat Toxicol (2019) 208 (January):126-37. doi: 10.1016/j.aquatox.2019.01.009

56. Wang Y, Liu W, Zhang Q, Zhao H, Quan X. Effects of Developmental Perfluorooctane Sulfonate Exposure on Spatial Learning and Memory Ability of Rats and Mechanism Associated With Synaptic Plasticity. Food Chem Toxicol (2015) 76:70-6. doi: 10.1016/j.fct.2014.12.008

57. Jantzen CE, Annunziato KM, Cooper KR. Behavioral, Morphometric, and Gene Expression Effects in Adult Zebrafish (Danio Rerio) Embryonically Exposed to PFOA, PFOS, and PFNA. Aquat Toxicol (2016) 180:123-30. doi: 10.1016/j.aquatox.2016.09.011

58. Li W, He QZ, Wu CQ, Pan XY, Wang J, Tan Y, et al. PFOS Disturbs BDNFERK-CREB Signalling in Association With Increased MicroRNA-22 in SHSY5Y Cells. BioMed Res Int (2015) 2015(7):1-10. doi: 10.1155/2015/302653

59. Guo XX, He QZ, Li W, Long DX, Pan XY, Chen C, et al. Brain-Derived Neurotrophic Factor Mediated Perfluorooctane Sulfonate InducedNeurotoxicity Via Epigenetics Regulation in SK-N-SH Cells. Int J Mol Sci (2017) 18(4):1-13. doi: 10.3390/ijms18040893

60. Zhang Y, Le T, Grabau R, Mohseni Z, Kim H, Natale DR, et al. TMEM16F Phospholipid Scramblase Mediates Trophoblast Fusion and Placental Development. Sci $A d v$ (2020) 6(19):eaba0310. doi: 10.1126/sciadv.aba0310

61. Pham A, Zhang J, Feng L. Exposure to Perfluorobutane Sulfonate and Perfluorooctanesulfonic Acid Disrupts the Production of Angiogenesis Factors and Stress Responses in Human Placental Syncytiotrophoblast. Reprod Toxicol (2020) 98:269-77. doi: 10.1016/j.reprotox.2020.10.013

62. Marinello WP, Mohseni ZS, Cunningham SJ, Crute C, Huang R, Zhang JJ, et al. Perfluorobutane Sulfonate Exposure Disrupted Human Placental Cytotrophoblast Cell Proliferation and Invasion Involving in Dysregulating Preeclampsia Related Genes. FASEB J (2020) 34(11):14182-99. doi: 10.1096/ fj.202000716RR

63. Orendi K, Gauster M, Moser G, Meiri H, Huppertz B. The Choriocarcinoma Cell Line BeWo: Syncytial Fusion and Expression of Syncytium-Specific Proteins. Reproduction (2010) 140(5):759-66. doi: 10.1530/REP-10-0221

64. Yang B, Ren Q, Zhang JC, Chen QX, Hashimoto K. Altered Expression of BDNF, BDNF Pro-Peptide and Their Precursor proBDNF in Brain and Liver
Tissues From Psychiatric Disorders: Rethinking the Brain-Liver Axis. Transl Psychiatry (2017) 7(5):e1128. doi: 10.1038/tp.2017.95

65. Mowla SJ, Farhadi HF, Pareek S, Atwal JK, Morris SJ, Seidah NG, et al. Biosynthesis and Post-Translational Processing of the Precursor to BrainDerived Neurotrophic Factor. J Biol Chem (2001) 276(16):12660-6. doi: 10.1074/jbc.M008104200

66. Balkowiec A, Katz DM. Cellular Mechanisms Regulating Activity-Dependent Release of Native Brain-Derived Neurotrophic Factor From Hippocampal Neurons. J Neurosci (2002) 22(23):10399-407. doi: 10.1523/JNEUROSCI.2223-10399.2002

67. Lieto A, Rantamäki T, Vesa L, Yanpallewar S, Antila H, Lindholm J, et al. The Responsiveness of Trkb to Bdnf and Antidepressant Drugs is Differentially Regulated During Mouse Development. PloS One (2012) 7(3):1-11. doi: 10.1371/journal.pone.0032869

68. Pradhan J, Noakes PG, Bellingham MC. The Role of Altered BDNF/TrkB Signaling in Amyotrophic Lateral Sclerosis. Front Cell Neurosci (2019) 13:368 Frontiers Media S.A. doi: 10.3389/fncel.2019.00368

69. Middlemas DS, Meisenhelder J, Hunter T. Identification of TrkB Autophosphorylation Sites and Evidence That Phospholipase C- $\gamma 1$ Is a Substrate of the TrkB Receptor. J Biol Chem (1994) 269(7):5458-66. doi: 10.1016/S0021-9258(17)37708-6

70. Segal RA, Bhattacharyya A, Rua LA, Alberta JA, Stephens RM, Kaplan DR, et al. Differential Utilization of Trk Autophosphorylation Sites. J Biol Chem (1996) 271(33):20175-81. doi: 10.1074/jbc.271.33.20175

71. Gupta VK, You Y, Gupta VB, Klistorner A, Graham SL. TrkB Receptor Signalling: Implications in Neurodegenerative, Psychiatric and Proliferative Disorders. Int J Mol Sci (2013) 14(5):10122-42. doi: 10.3390/ijms140510122

72. Nagappan G, Woo NH, Lu B. Ama"Zinc" Link Between TrkB Transactivation and Synaptic Plasticity. Neuron (2008) 57(4):477-9. doi: 10.1016/j.neuron. 2008.02.004

73. Msheik H, El Hayek S, Bari MF, Azar J, Abou-Kheir W, Kobeissy F, et al. Transcriptomic Profiling of Trophoblast Fusion Using BeWo and JEG-3 Cell Lines. Mol Hum Reprod (2019) 25(12):811-24. doi: 10.1093/molehr/ gaz061

74. Rothbauer M, Patel N, Gondola H, Siwetz M, Huppertz B, Ertl P. A Comparative Study of Five Physiological Key Parameters Between Four Different Human Trophoblast-Derived Cell Lines. Sci Rep (2017) 7(1):5892. doi: 10.1038/s41598-017-06364-z

Conflict of Interest: The authors declare that the research was conducted in the absence of any commercial or financial relationships that could be construed as a potential conflict of interest.

Publisher's Note: All claims expressed in this article are solely those of the authors and do not necessarily represent those of their affiliated organizations, or those of the publisher, the editors and the reviewers. Any product that may be evaluated in this article, or claim that may be made by its manufacturer, is not guaranteed or endorsed by the publisher.

Copyright (c) 2021 Marchese, Li, Liu, Zhang and Feng. This is an open-access article distributed under the terms of the Creative Commons Attribution License (CC BY). The use, distribution or reproduction in other forums is permitted, provided the original author(s) and the copyright owner(s) are credited and that the original publication in this journal is cited, in accordance with accepted academic practice. No use, distribution or reproduction is permitted which does not comply with these terms. 